\title{
Reuse, recycle, and shine: using everyday objects to teach optics
}

Erick Burgos Parra, Gloria Segovia Alvear

Erick Burgos Parra, Gloria Segovia Alvear, "Reuse, recycle, and shine: using everyday objects to teach optics," Proc. SPIE 10741, Optics Education and Outreach V, 107410I (22 February 2019); doi: 10.1117/12.2321162

SPIE Event: SPIE Optical Engineering + Applications, 2018, San Diego, California, United States 


\title{
Reuse, recycle, and shine: using everyday objects to teach optics
}

\author{
Erick Burgos-Parra*a, Gloria Segovia Alvear ${ }^{\mathrm{b}}$ \\ ${ }^{a}$ Department of Physics and Astronomy, University of Exeter, EX4 4QL Exeter, United Kingdom; \\ ${ }^{\mathrm{b}}$ First Steps Community Playgroup, EX4 7DQ Exeter, United Kingdom
}

\begin{abstract}
It is not always possible to have access to commercial experimental kits in order to impart knowledge to a class or perform an outreach presentation, and this often happens because of the lack of funding in schools and universities. We aimed to create an outreach demonstration using only recyclable materials and reusing old CDs or DVDs, so that everyone can use it. In this work, we present the outreach activity "Homemade spectrometer using a CD/DVD", which won the first place in the Optics Outreach games 2017 in San Diego. This spectrometer can be built with a CD or DVD and a template that can be acquired for free by emailing the University of Exeter Optics and Photonics Society (EUOPS), or can be collected in our outreach activities. We have tested this outreach demonstration in several events during 2017 and 2018 with a very positive feedback. Teachers and students within UK, USA, Mexico and Chile have required the activity worksheet in order to replicate the demonstration at their institutions.
\end{abstract}

Keywords: Diffraction, spectrometer, rainbow, colors, CD, homemade, recycle, reuse.

\section{INTRODUCTION}

Teaching science is much easier when your learning is hands-on and you perform experiments. This applies to teaching optics very well: since vision is our dominant sense, it is easier for us to trust and understand what we see more than any other stimulus. However, it is not always possible to have access to experimental kits in classrooms or even in universities. This is often true in low- and middle-income countries where the government expenditure on education is less than a $5 \%$ of their GDP as of 2010, almost a $0.9 \%$ under the average expenditure of high-income countries [1]. A similar scenario can be found in low-income schools in high social risk sectors of all countries. In order to overcome the restrictions created by the lack of funding, teachers and professors have often used recycled equipment and everyday materials in order to create experiments. Initiatives like "Dumpster optics" kit [2] or some of the experiments found in the web page "Practical Physics" by the Institute of Physics [3] are good examples of how to create experimental kits at very low cost, using mostly recycled items for providing an excellent explanation for optical phenomena such as diffraction, refraction, and reflection among others. In this work, we present an outreach activity where the participants must build a spectrometer using everyday recyclable materials. We give a great emphasis to the concept of recycling and reusing. For instance, we encourage the participants to use old CDs and DVDs to build their spectrometers. Finally, an experiment sheet is provided to replicate the experiment and the construction of the spectrometer in classrooms, outreach sessions and for personal use.

\section{BACKGROUND}

\subsection{University of Exeter Optics and Photonics Society}

The University of Exeter Optics and Photonics Society (EUOPS) was established in 2016 and comprised the members of the SPIE student chapter founded in 2014 and the OSA student chapter founded in 2016. Its goal is to promote an environment for sharing ideas and events related with the communication of science at all levels, and the professional development of its members. The society has chosen to focus its efforts in promoting science to a non-specialist audience, most commonly pre-university students, through outreach sessions in different events and locations around Devon, UK.

*eoburgos@ug.uchile.cl

Optics Education and Outreach V, edited by G. Groot Gregory, Proc. of SPIE Vol. 10741, 107410 I

(C) 2018 SPIE · CCC code: 0277-786X/18/\$18 · doi: 10.1117/12.2321162 


\subsection{Optics Outreach Games 2017}

The design of the "Homemade spectrometer with a CD or DVD" was created to participate in the Optics Outreach Games 2017 (OOG) held within the SPIE Optics and Photonics 2017 conference in San Diego, USA. OOG is an instance to share optics and photonics demonstrations from student chapters worldwide. We aimed to create an outreach demonstration with an important optics content, as it is the explanation of the formation of colors spectrums through diffraction. We also aimed to create a demonstration fully reproducible anywhere. In order to do this, we created a worksheet that contains all the information required to perform the demonstration and build the spectrometer. This worksheet can be acquired from EUOPS in every outreach session or by emailing EUOPS (euops@exeter.ac.uk).

\section{HOMEMADE SPECTOMETER USING A CD OR DVD}

\subsection{Aims of the activity}

The aims of the activity are the following:

- To answer the question "Why do CDs reflect rainbow colors?"

- To understand the physical phenome of diffraction by a grating

- To create awareness of the importance of recycling and reusing materials to do experiments

- To create a replicable, low-cost and shareable outreach demonstration.

\subsection{Description of the activity}

The demonstration starts by delivering a document to the participants that contains the information required to understand the goals of the activity, the physics behind the experiment, a template to build a spectrometer, examples of the results that they should get after building the device and extra activities to carry-on. The full document is provided as an appendix of this paper.

The first part of the demonstration is hands-on. Here, the demonstrator defines what a spectrometer is and what it does. After a short introduction, the participants are invited to create their own spectrometer using the template provided at the end of the distributed document. This part of the activity can last from 10 to 15 minutes depending on the expertise and manual skills of the participants. It is recommended to encourage the use of recyclable items to build the spectrometer e.g. an old CD or DVD and a cereal box painted in black to stick on the template. It is important to restrict the passage of light from other places except the slit formed by the shutter. In order to do that, the cardboard has to be as opaque as possible. Figure 1(a) shows the materials needed to build the spectrometer and figure 1(b) the final spectrometer. 


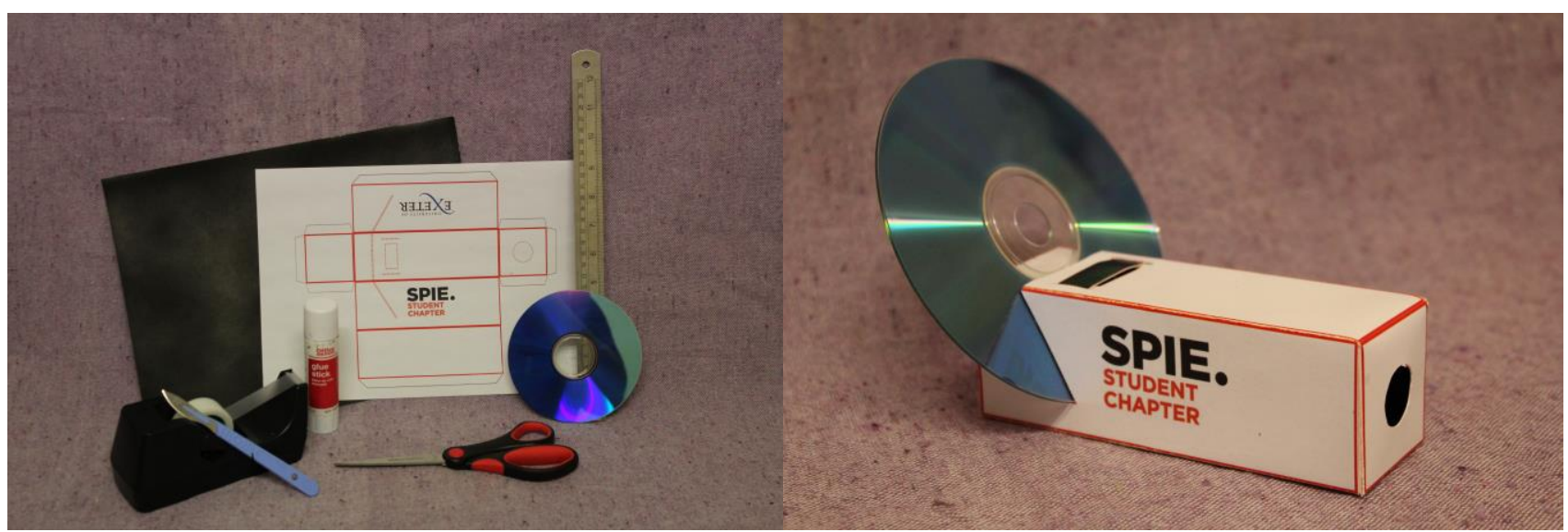

Figure 1. (a) Materials need to build a homemade spectrometer. A cereal box cardboard can replace the opaque cardboard shown in the figure (left). (b) A finished homemade spectrometer (right)

The second part of the demonstration is mostly expositive. Here, the scientist or teacher establishes the question, "Why do CDs reflect rainbow colors?" and introduce the concepts of diffraction, diffraction gratings, spectra and colors as wavelengths. Using their own spectrometer, participants should look for different light sources and compare them with the examples provided in the worksheet. The daylight and fluorescent lightbulbs are the most common light sources used in most of the outreach sessions and they are a good start to test the functioning of the device. It is critical to have a slit of $\sim 0.5 \mathrm{~cm}$ wide to obtain a good spectrum. The size of the slit can be modified by moving the shutter.

Finally, the activity concludes by encouraging the participants to try different light sources and to discover what elements are producing that light emission. This must be done by comparing the acquired spectrum with the information provided on the data sheet containing the light spectrum produced by all the elements in the periodic table [4]. This data is from MIT Wavelength Tables and the NIST Atomic Spectrum Database [5].

\subsection{Health and Safety}

In general, this is a safe demonstration, which does not require demonstrators to carry out any specific health and safety training. The following rules of thumb should serve as general advice:

- When doing the activity with children below 6 years, the presence of an extra adult to help children cutting the template is recommended. The template must be pasted onto a cardboard and children might have problem cutting it by themselves.

- Cutting the two small slits to insert the shutter might be tricky without a cutter or a scalpel. Only adults with experience using these elements must cut them when using sharp edges.

- Due to the size of the slit generated by the shutter, the intensity of observed spectra is safe for the human eye. However, never allow the participants to look directly into the bright light sources like the sun or eclipses with a naked eye. In addition, do not allow participants to go too close to hot sources such as flames or intense lightbulbs.

- When looking through the visor (round hole) the field of vision is obstructed by the spectrometer. Do not allow participants to walk around while using the spectrometer as this might cause accidents.

\section{OUTPUTS AND PUBLIC RECEPTION}

The general reception by the public has been positive, with several requests from different schools around Devon and other countries.

\subsection{Winners of the Optics Outreach Games 2017}

The "Homemade spectrometer using a CD" outreach demonstration won the first place at the Optics Outreach Games 2017 in San Diego. We have very positive comments related to the simplicity and effectiveness of the device, and on the 
concept of recycling and reuse used as part of the demonstration. People from different places and positions around the world took worksheets to replicate the demonstration at their institutions and outreach sessions.
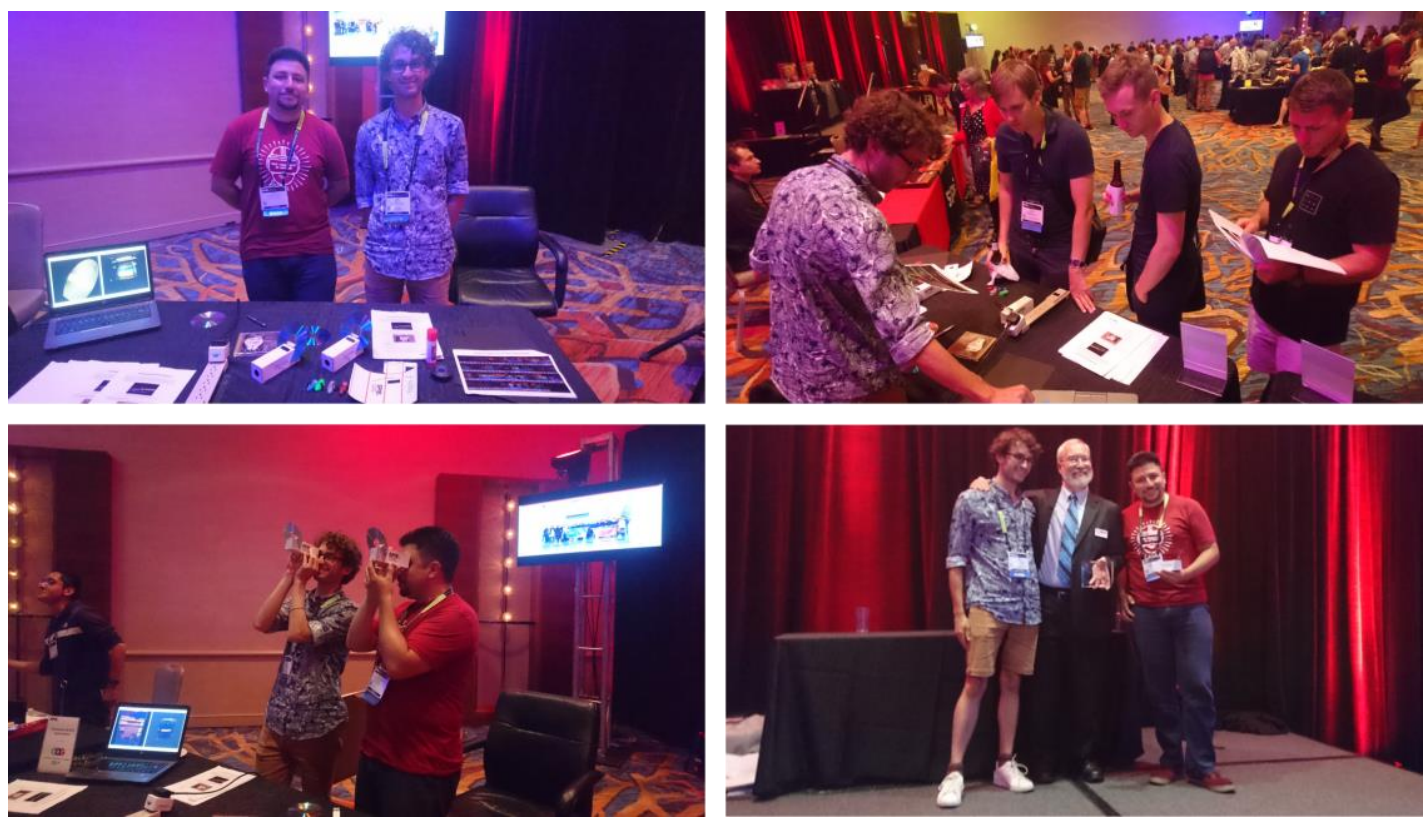

Figure 2. Outreach Optics Games 2017 contest held in San Diego. Top left: Erick Burgos Parra and Jake Mehew from the University of Exeter presented the activity during the contest. Top right: attendants of the outreach sessions participating of the activity. Bottom left: Erick and Jake using the spectrometer. Bottom right: Erick and Jake being awarded with the $1^{\text {st }}$ place of the contest.

\subsection{Sidmouth Science festival 2017}

The "Sidmouth Science festival" is a scientific festival that started in 2012 in the city of Sidmouth, UK. In 2017 it lasted 13 days with over 4400 attendances during the week [6]. The event is aimed at all ages and abilities and most events are free to attend, as it can be seen in Figure 3. EUOPS set-up a stand on Saturday the $14^{\text {th }}$ of October, 2017 presenting different demonstrations related to optics with one of them being "Build your own spectrometer with a CD". The stand received more than 300 people during the day and about 30 participants built their own spectrometer. We provided a CD to test it in the place, but we encouraged them to use one of their own CDs at home.

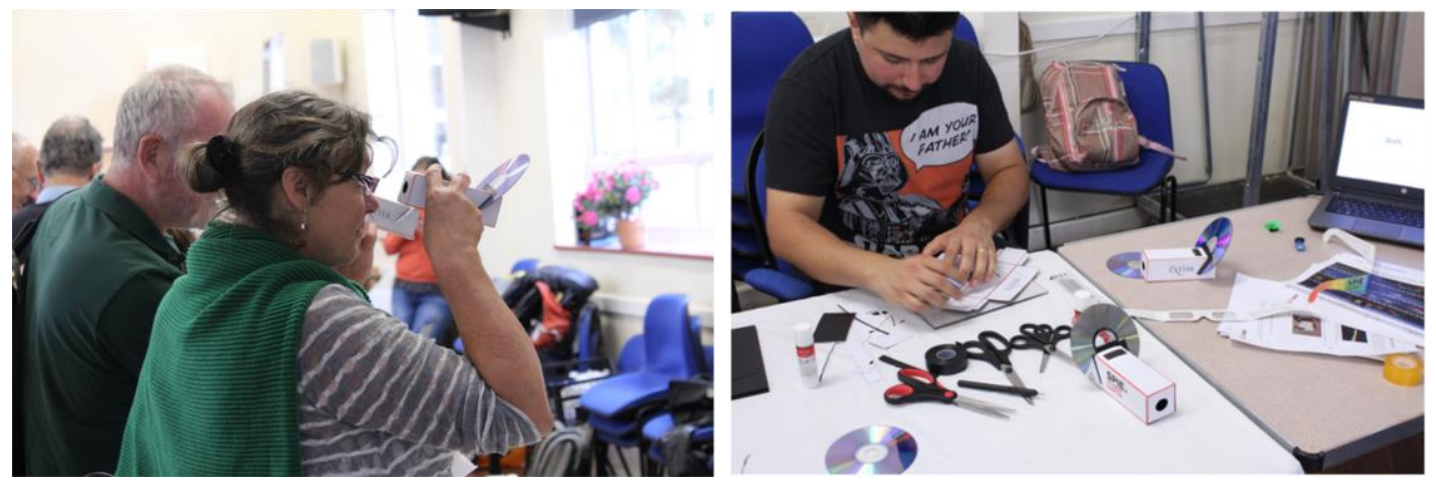

Figure 3. People from all age groups attended Sidmouth Science Festival 2017 (left). A member of EUOPS explaining how to make a homemade spectrometer (right). 


\subsection{International day of Light 2018 - Outreach in the streets}

This year is the first time that the International Day of Light is celebrated around the world. More than 500 events took place in 87 countries to create awareness of the role that light plays in science, culture and art, education, sustainable development, and in fields as diverse as medicine, communications, and energy.

EUOPS organized two main events that included the entire community of Exeter. We held a photo competition open to everyone in UK with three main categories which encouraged participants to find how important light is in nature, in their day-to-day life and in technology. In addition, we organize a multi-disciplinary outreach session including scientists from physics, engineering, biophysics, astrophysics and archaeology. We reached around 50 people, most of them adults. We received very good feedback on all the outreach demonstrations, which included the homemade spectrometer.

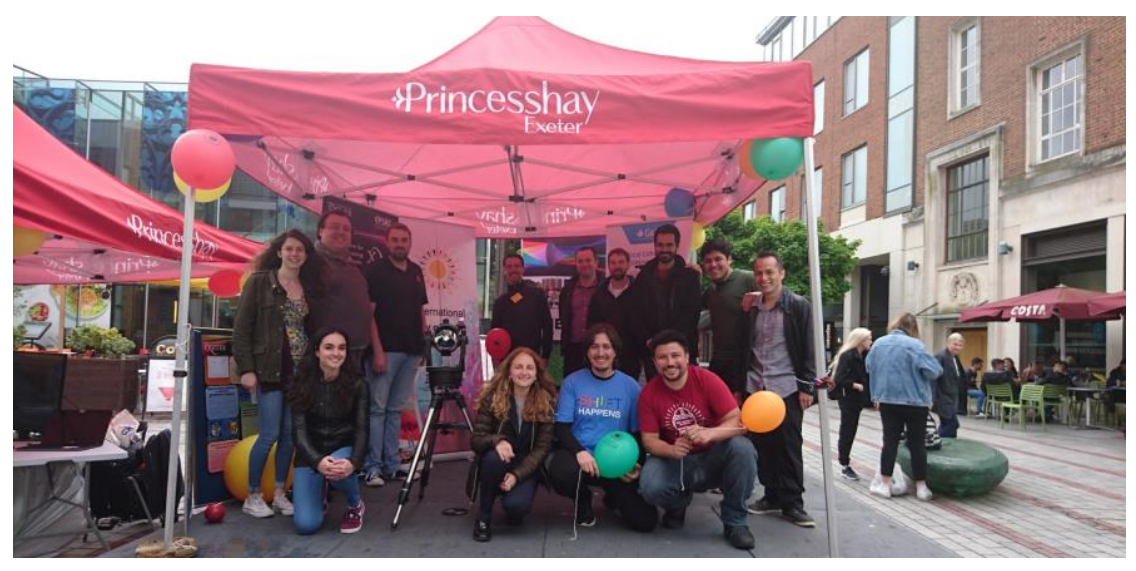

Figure 4. The multi-disciplinary team that carried out the outreach activity in Exeter's city center, UK.

\subsection{Lighting up RAMM}

On Saturday the 21st of July, 2017 EUOPS members and students of the CDT in Metamaterials XM2 of the University of Exeter (UoE) (Figure 5) organized an outreach session in the Royal Albert Memorial Museum (RAMM) and Art Gallery in Exeter to show hands-on experiments and demonstrations related with the permanent exhibition held by the museum. More than 150 visitors [7] participated in the various activities carried out on that day such as conduction of metals, superconductivity, graphene based circuits, metamaterials in birds and insects, acoustics experiments and handson mixing of colors, and creating your own spectrometer with a $\mathrm{CD}$. Both children and adults enjoyed making the spectrometer and using it around the museum. A local artist took a couple of copies of the worksheet to teach their students how to build the device and try to get an artistic output from it, giving an artistic twist to the demonstration. Teachers from local schools also asked for copies to run the experiment in their classrooms. 

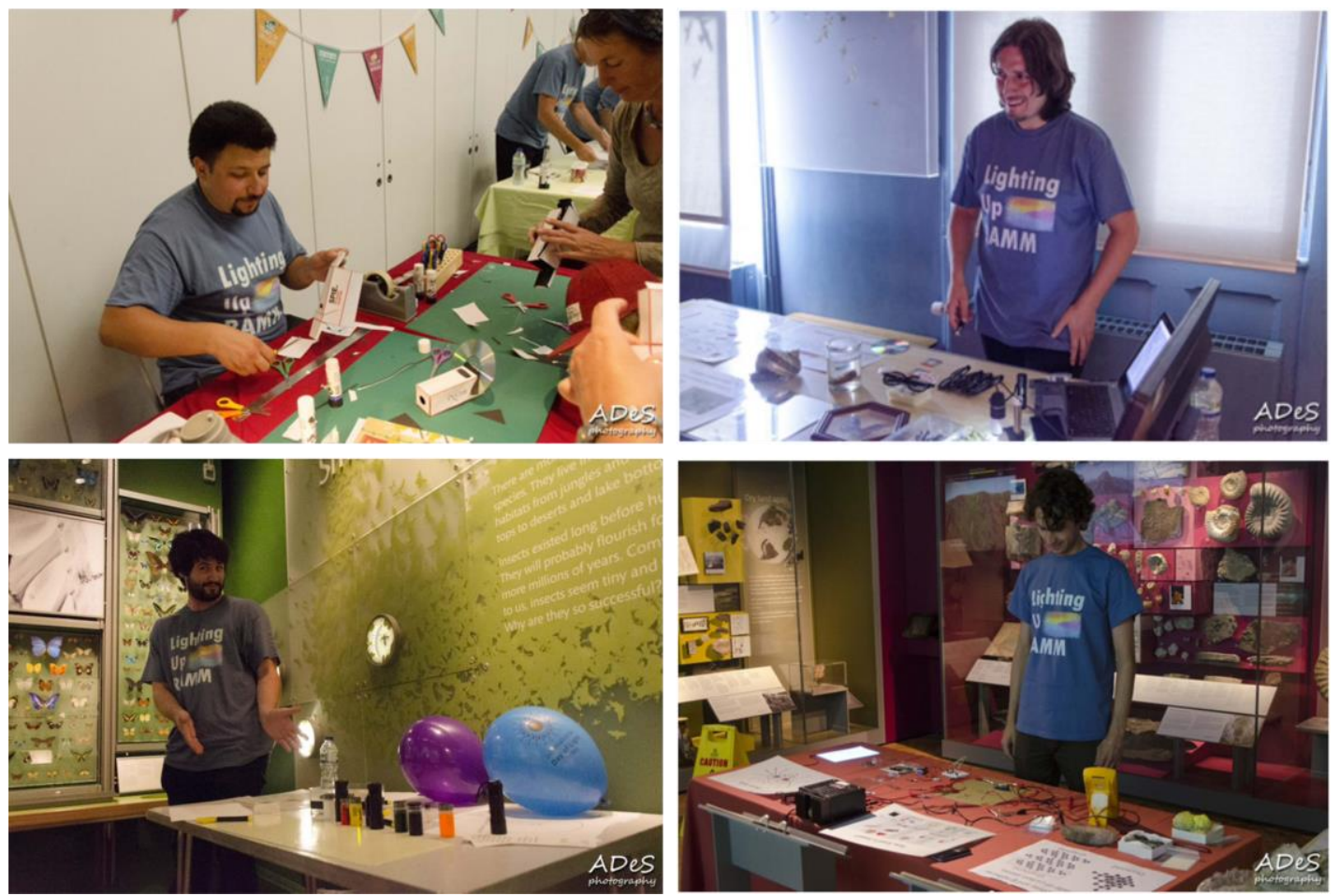

Figure 5. Different stands presented in the outreach activity "Lighting up RAMM: Top left: Build your own spectrometer with a CD. Top right: Iridescent animals and metamaterials. Bottom left: Fluorescent bugs and liquids. Bottom right: conductivity and magnetism of different materials. Pictures by Adolfo De Sanctis, UoE.

\subsection{Sharing the activity around the world}

In each outreach session teachers, students and general public have taken copies of the worksheet that contains the full activity. However, people from other countries have required the activity to replicate it in their own outreach sessions and classrooms:

- The officer of the SPIE student chapter at the University of Arkansas in the US required a copy to perform an outreach session. People's feedback was very good. In his words: "People certainly did enjoy the activity related to the CD spectrometer" They also brought along a commercial spectrometer so that participants could see how a commercial one works and build their own to better understand the workings of the commercial device. The visiting students were of high school age ( 14 - 18).

- A high school teacher from Santiago, Chile used the activity in her classroom to teach light diffraction. Students came up with different designs for the exterior of the spectrometer. An example of it can be seen in Figure 6 . The activity was very successful and the educational value of the demonstration fulfilled the goals of the planning of the class 


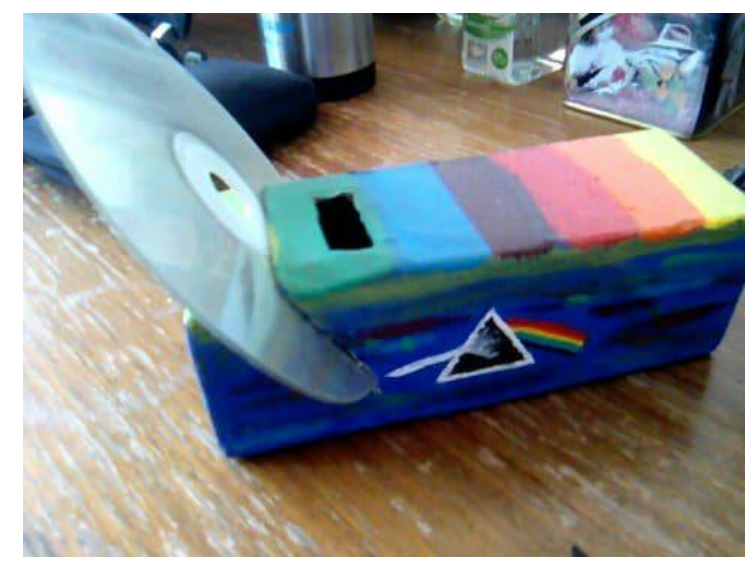

Figure 6. An unfinished homemade spectrometer built by students from a Chilean high school. They modified the external design to make it unique.

\section{SUMMARY}

In summary, we have created an outreach demonstration based on building a spectrometer with a CD or a DVD. The new design of the spectrometer allows the modification of the size of the slit that collects light to produce the diffraction spectra. The demonstration is comprised within a document will full explanation of the steps to build the spectrometer, a simple explanation of the light phenomenon of diffraction, examples of spectra taken with the device, a template to build the spectrometer and a data sheet with the spectrum for each element of the periodic table. The full document is provided as an appendix of this paper for general use. We have carried out outreach sessions implementing this demonstration with a positive public reception and feedback. People like the simplicity of the demonstration and how easy it is to build the spectrometer. In addition, people sympathize with the idea of recycling and reusing materials to build the spectrometer and to extend the idea of recycling and reusing in their day-to-day life. Finally, students, artists and teachers from UK, Mexico, Chile and USA have asked for permission to reproduce the activity in their respective institutions and outreach sessions using the worksheet provided during the activity.

\section{ACKNOWLEDGMENTS}

We acknowledge financial support from SPIE, OSA and the Engineering and Physical Sciences Research Council (EPSRC) of the United Kingdom, via the EPSRC Centre for Doctoral Training in Metamaterials (Grant No.

EP/L015331/1).

\section{REFERENCES}

[1] Max Roser and Esteban Ortiz-Ospina (2018) - "Financing Education". Published online at OurWorldInData.org. Retrieved from: 'https://ourworldindata.org/financing-education' [Online Resource] (04 September 2018)

[2] Judy Donnelly, Nancy Magnani, Kathleen Robinson, "Dumpster Optics: teaching and learning optics without a kit," Proc. SPIE 9946, Optics Education and Outreach IV, 99460G (29 September 2016); doi: $10.1117 / 12.2238930$

[3] "Practical Physics", http://www.practicalphysics.org (04 September 2018)

[4] Julie Gagnon, "Visible Spectra of the Elements", http://www.umop.net/spctelem (05 September 2018)

[5] Atomic Spectra Database, https://www.nist.gov/pml/atomic-spectra-database (05 September 2018)

[6] Sidmouth $\quad$ Science $\quad$ Festival 2017 Review, http://www.sidmouthsciencefestival.org/sites/default/files/users/common/review17.pdf (06 September 2018)

[7] Anja Roeding, "Lighting up RAMM - XM2 PGRs in the Royal Albert Memorial Museum", http://blogs.exeter.ac.uk/xm2news/ramm2018/ (06 September 2018) 


\section{Homemade spectrometer using a CD}

A spectrometer is a device that separates light into its different component wavelengths. Depending on the source of the light, you might decompose it into the entire visible spectrum (like a rainbow) or find out that only certain wavelengths (colors) make up the source. Knowing which colors you can get from a source of light, you can determine what is actually producing that light.

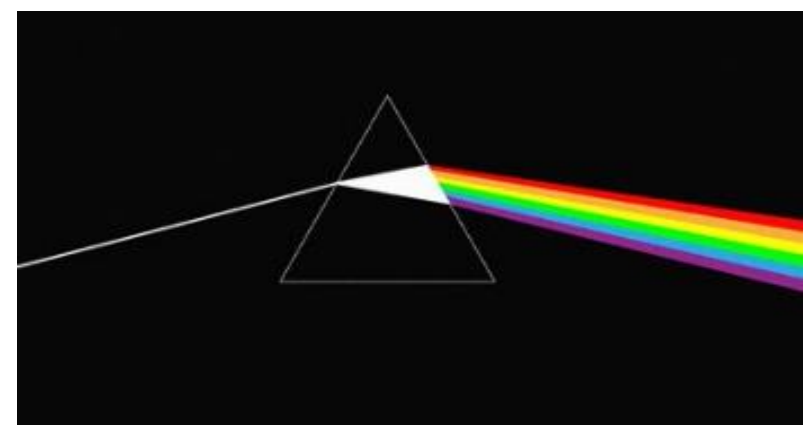

Figure 7. Decomposition of the light through a prism (from Getty images).

\section{How to make your own spectrometer.}

In order to create a portable homemade spectrometer, we will need the following materials:

Figure 8. Materials needed to build the spectrometer.

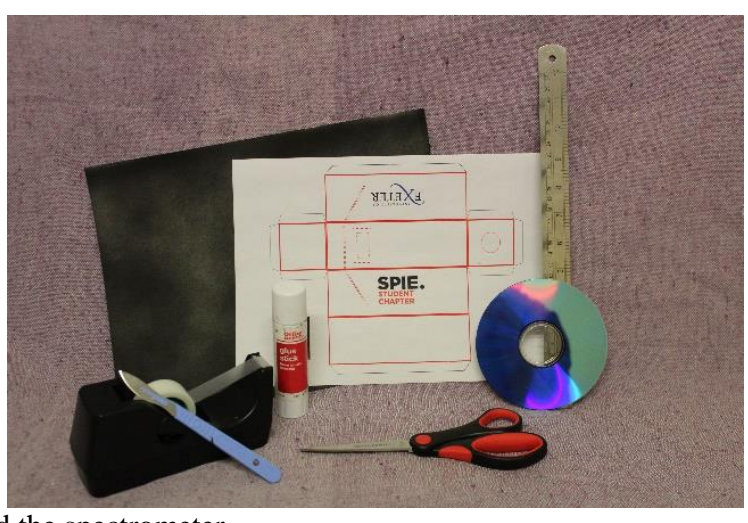

- A piece of opaque cardboard. Try using the cardboard of a cereal box.

- Glue stick

- $\quad$ Adhesive tape

- Scissors

- A cutting knife or scalpel

- $\quad$ An old CD or DVD.

- $\quad$ The homemade spectrometer template provided with this document

Let us stick the spectrometer template on one side of the cardboard. If your cardboard has just one black side, leave that side free and stick the template sheet on the opposite side. 


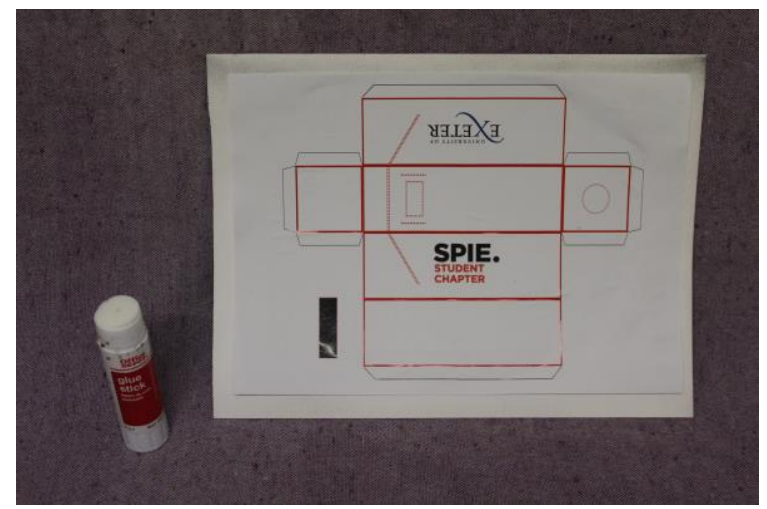

Figure 9. Take care of use a cardboard flexible enough to bend it later.

Cut the region delimited by the red lines. Do not forget to cut the shutter (black rectangle).

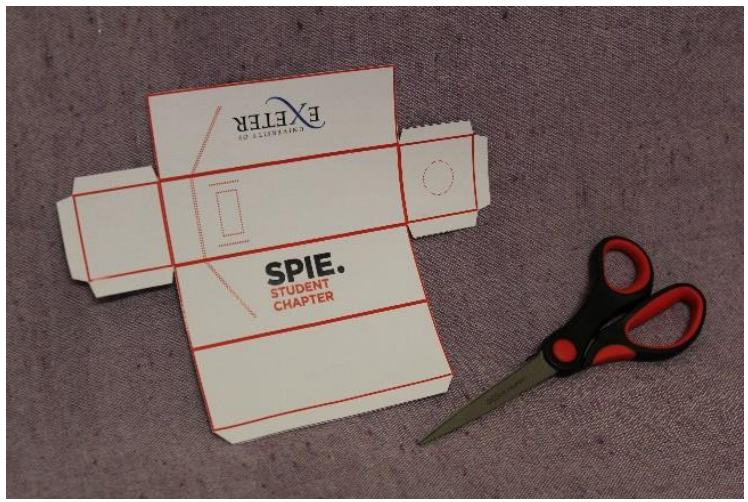

Figure 10. If you cannot cut thorugh the cardboard, ask for help to an adult.

With care, cut the dashed line with the cutting knife or scalpel. You should produce a slit for inserting the CD or DVD, an aperture to let the light enter, two small slits to fit the shutter and a circle to observe the color spectrum.

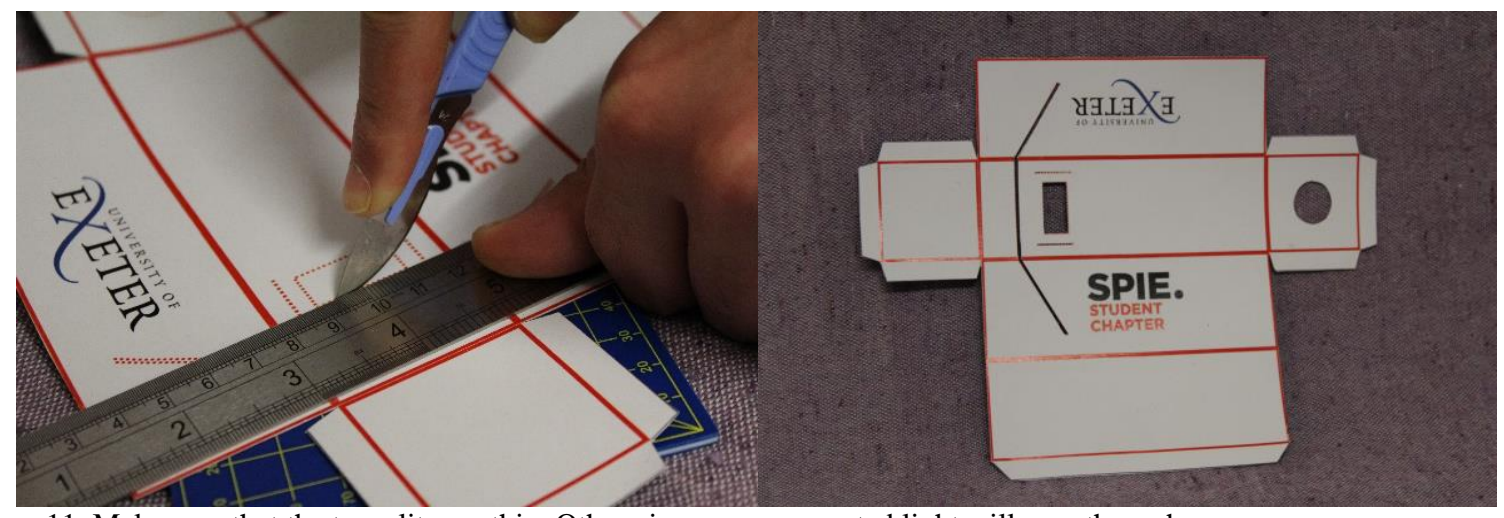

Figure 11. Make sure that the two slits are thin. Otherwise, some unwanted light will pass through

Use the reverse of your cutting knife or scalpel to go over of each solid red line. This will help you to bend the wings and the sides of the cuboid easily. Stick the long wing to the opposite side of the rectangle. Close the cuboid. You may find it helpful to use some adhesive tape. 


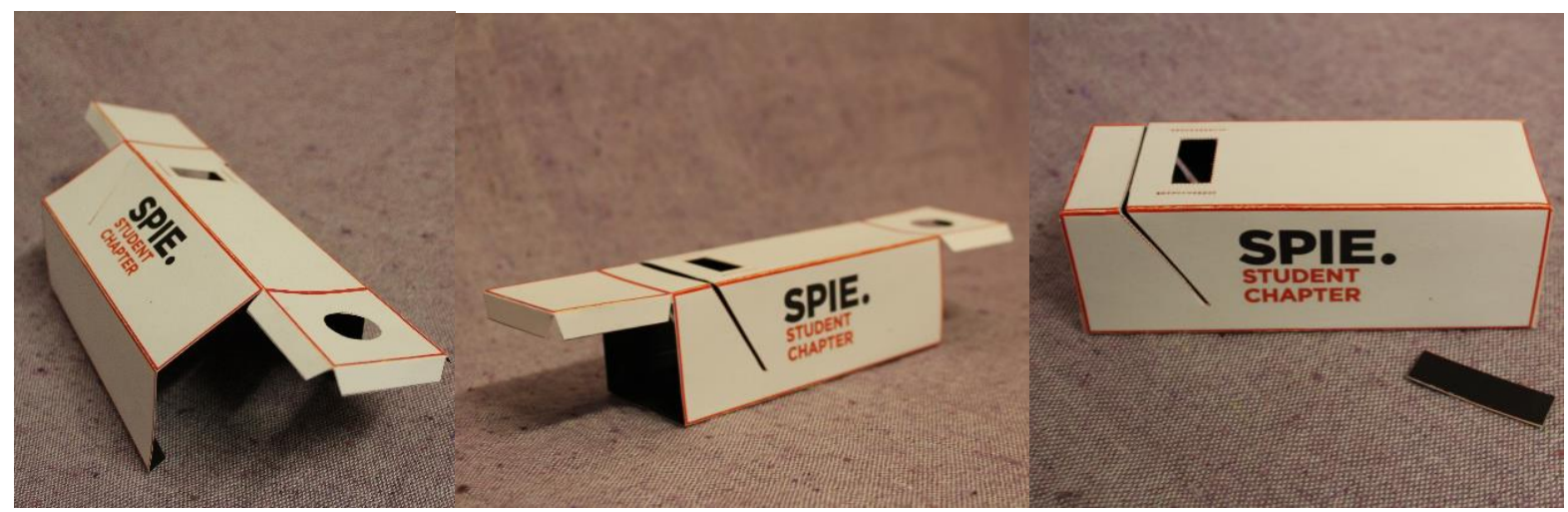

Figure 12. Bend and stick the template. Do not forget to fit the shutter in the slits.

Carefully place your CD or DVD into the big slit.

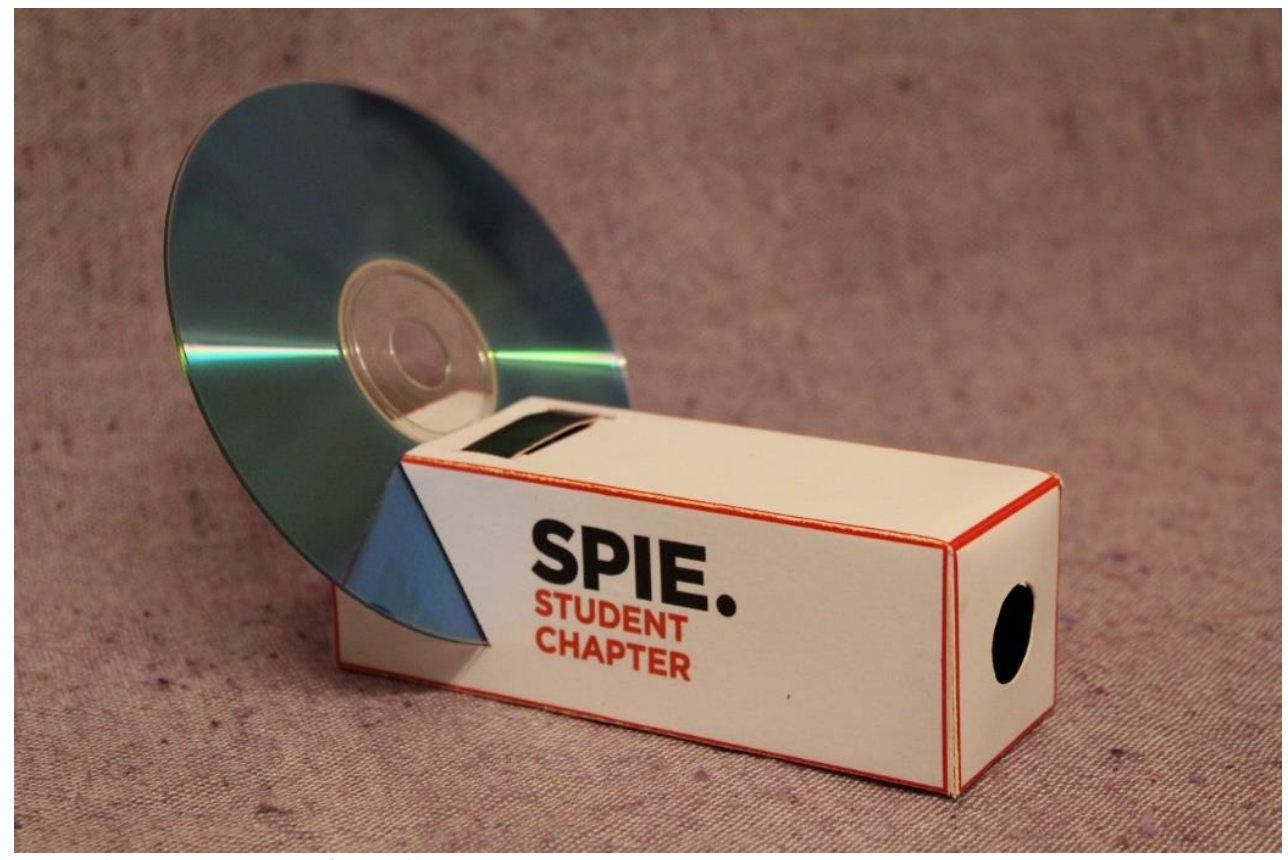

Figure 13. Homemade spectrometer using a CD.

Your homemade spectrometer is ready to use!

\section{How to use your spectrometer.}

Find a light source that you would like to analyze. Point the small slit formed between one edge of the aperture and the shutter towards the light. You can modify the size of the slit moving the shutter. A slit too narrow will produce a dim spectrum but a slit too wide produce a blurred one. Try to adjust the shutter to create a slit of around $0.3 \mathrm{~mm}$. A beam light must pass through the small slit and hit the CD. Look through the round aperture and you will see the decomposition of that beam light into the different wavelengths (colors). You can use your phone camera to capture the color spectrum and compare different sources. 


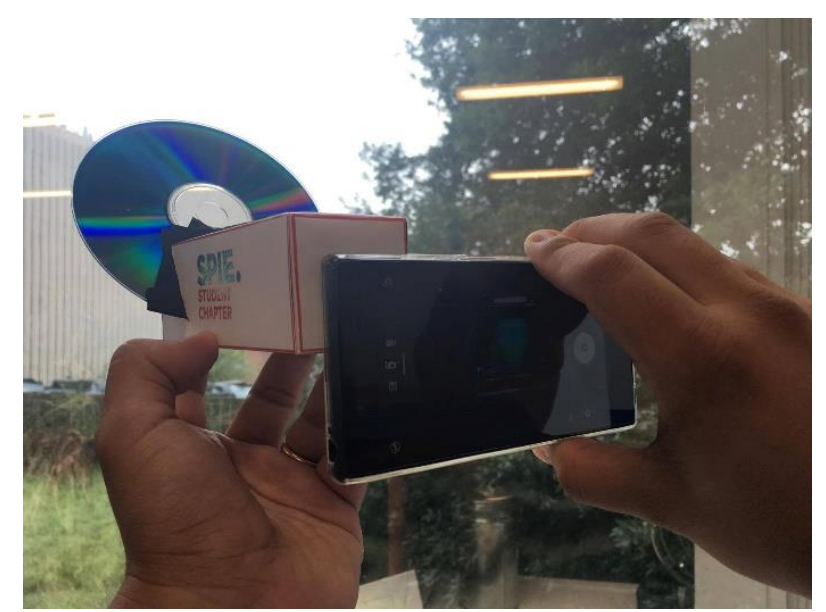

Figure 14. Use your phone to take pictures of the spectra that you obtain from different sources.

\section{How does this work?}

The physics principle that makes possible a spectrometer works is diffraction. Light can behave as a particle and as a wave and in this case, we are using a wave picture of the light to decompose it. In a similar way that you get a rainbow when you pass white light through a prism, you can get a rainbow if you pass light through a grating with small slits. However, these two types of rainbows are form due to different light phenomena. Rainbows in the sky after a rainy day, or the decomposition of white into colors by a prism are cause by a phenomenon called refraction. The colors produced by an oil stain in the street, or on the shiny side of a CD-ROM are produce by a phenomenon called diffraction

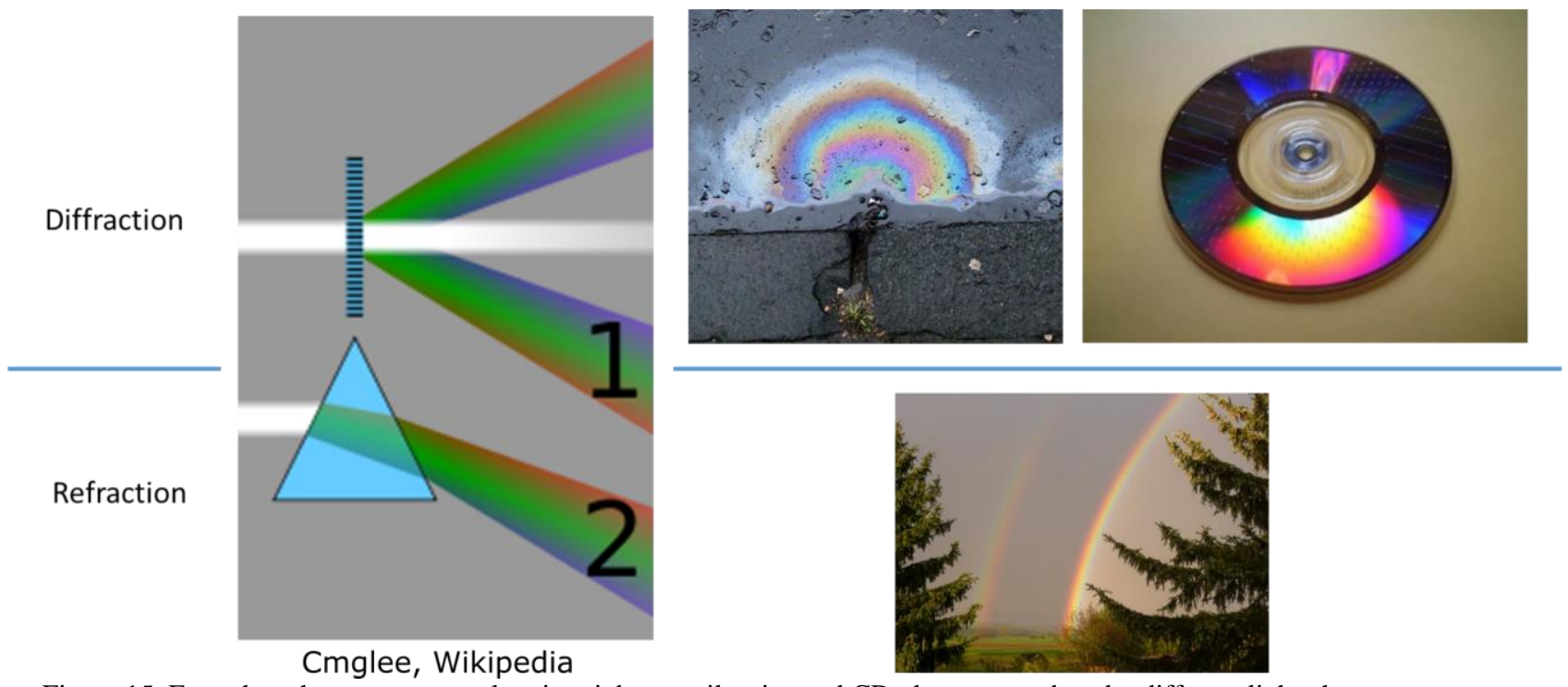

Figure 15. Even though you can see colors in rainbows, oil stains and CD, they are produce by different light phenomena

Diffraction is the bending of waves around the corners or edges of an obstacle or aperture. What kind of obstacles does a CD have? If you could see really close onto a CD or a DVD surface, you would see thousands of tracks separated all by the same distance. These devices store the information in these tracks and each millimeter of CD-ROM contains 625 tracks, which gives us tracks separated by 1.6 micrometers. A DVD contains twice as many tracks than a CD in each millimeter 

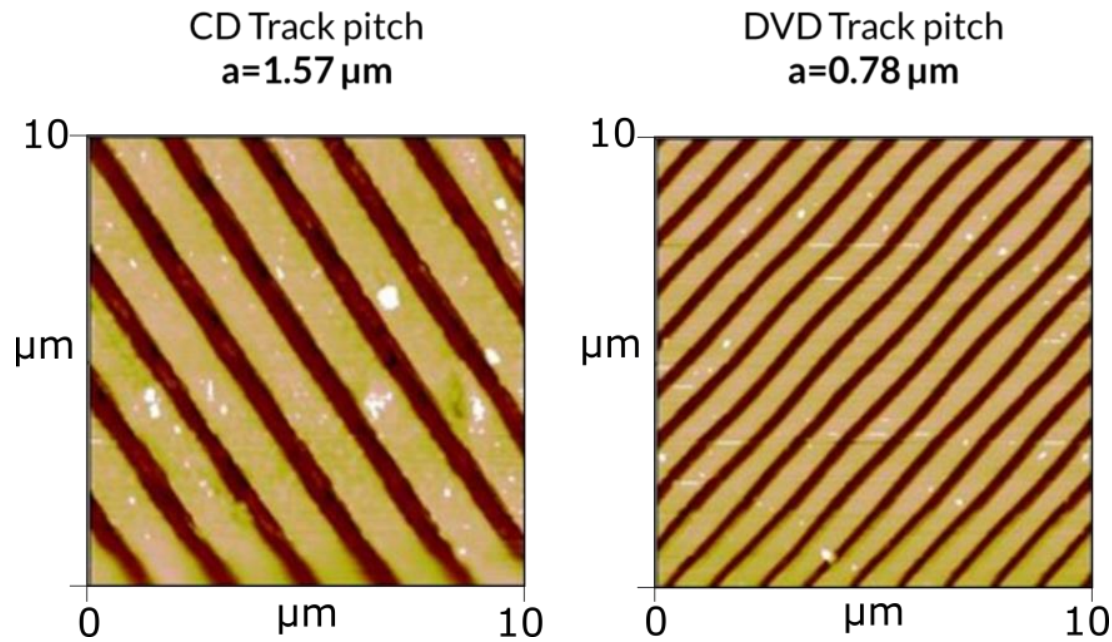

Figure 16. Images taken with an atomic force microscope of the micrometric tracks on the surface of a CD (left) and a DVD (right).

These tracks have to be around the same size as the wavelengths that we are trying to decompose and, for visible colors, that goes between $400 \mathrm{~nm}$ and $700 \mathrm{~nm}$. The tracks of a compact disc acts as something called a diffraction grating and separates light into its different components.

A white light source must contain in it all the colors of the visible spectrum, and each color has an associated wavelength. If you shine white light onto a CD or DVD, you should see the formation of a rainbow with all the visible colors on it. The rainbow is formed because each color is diffracted into a different angle. The bigger the wavelength (or the closest to the red) is that color the bigger is the diffraction angle and vice versa. In this way, each color arrives to a different position in your eye, forming a rainbow.

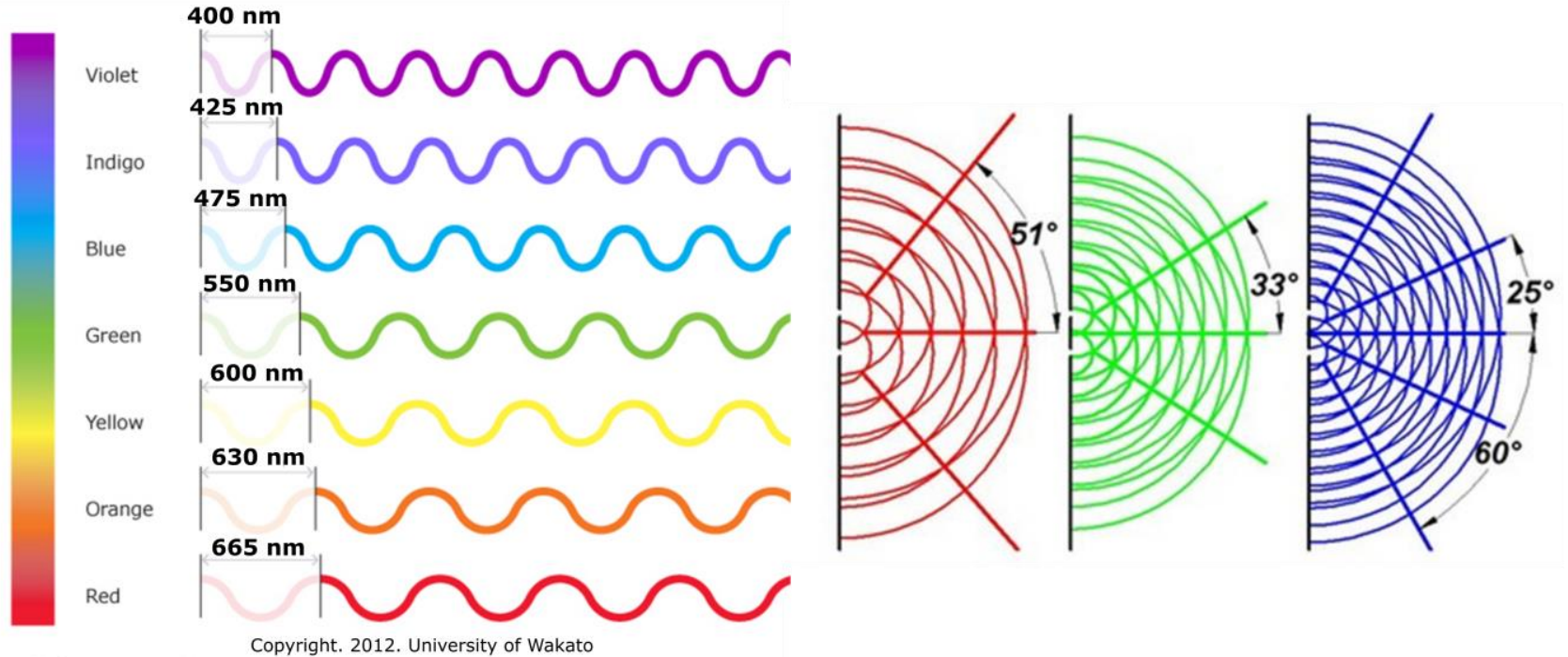

Figure 17. Wavelength corresponding to some colors of the visible spectrum (left). Angles of diffraction for different colors (right)

However, not all the light sources contain all the colors. It does depend of element of the periodic table that that light source uses to produce light! 
These are some examples of spectra taken with our homemade spectrometer pointed at different light sources:
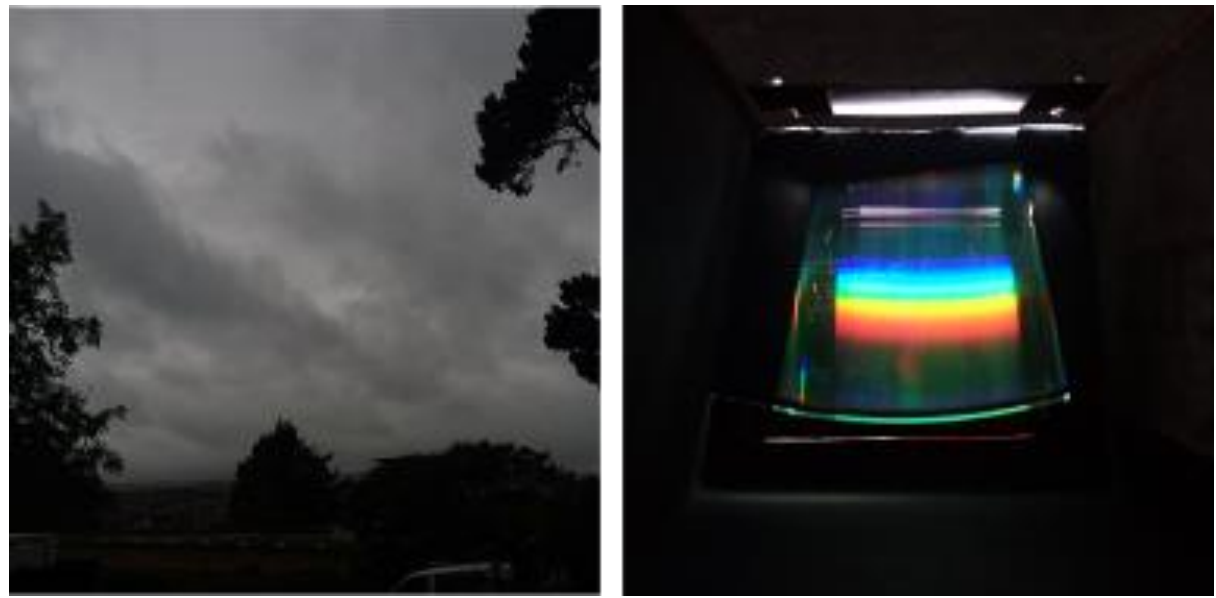

Figure 18. Spectrum of a Cloudy day. Sunlight contains all the colors in the visible spectrum.
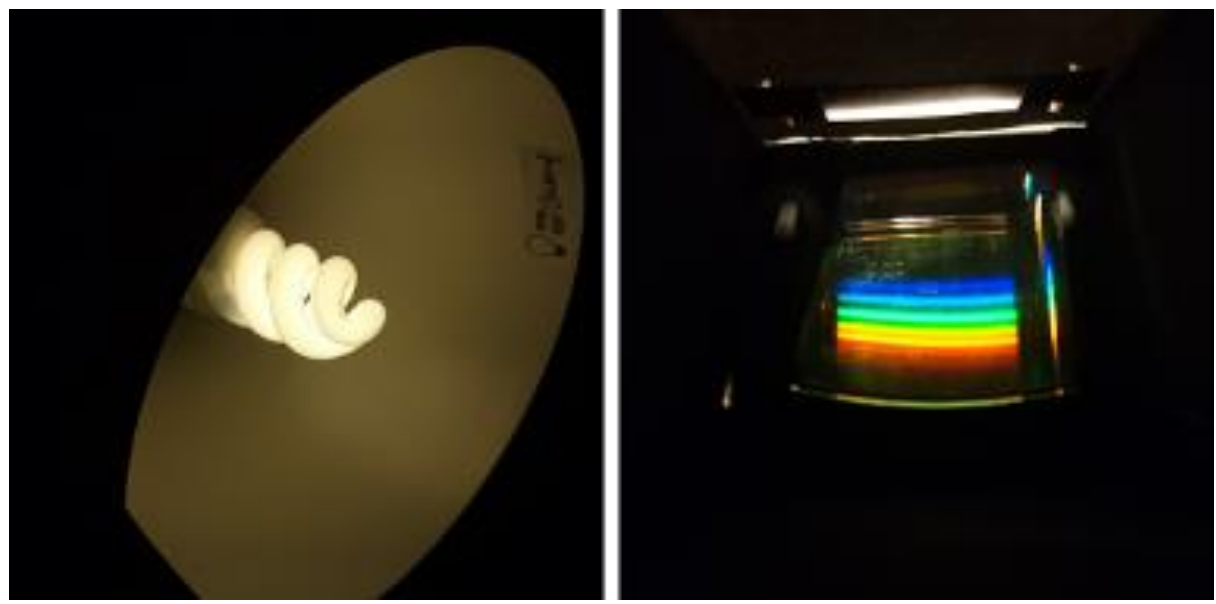

Figure 19. A fluorescent bulb consists of tubes that are filled with molecules of different elements such as mercury, argon, neon or xenon. Its spectrum contains a few discrete colors of the rainbow.
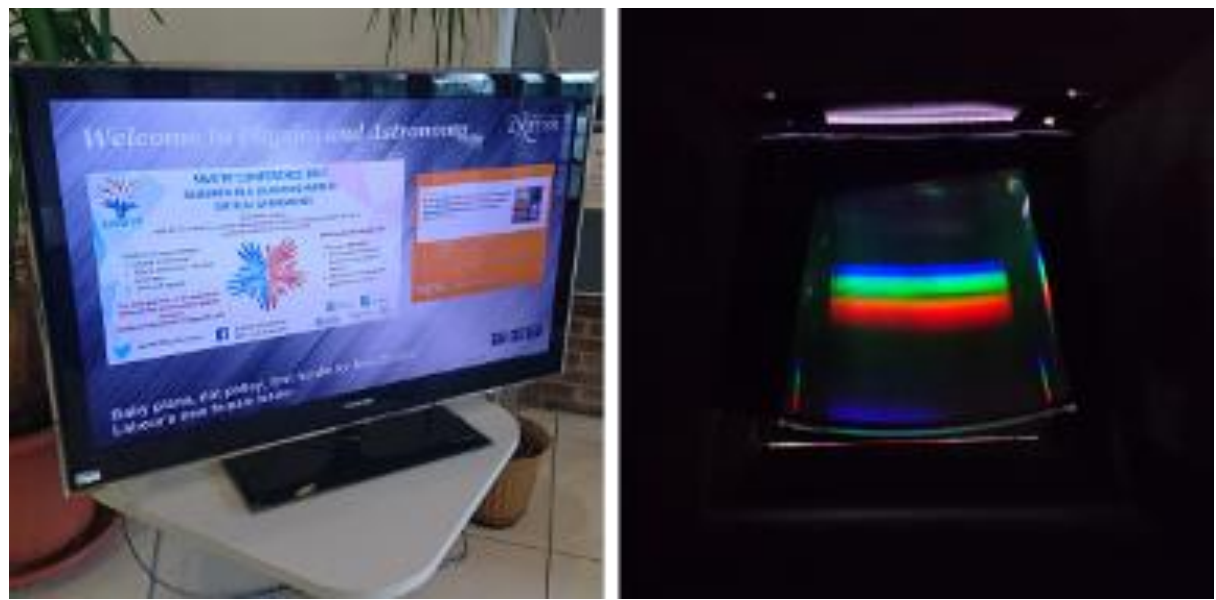

Figure 20. An LCD screen contains pixels that can produce only three colors: red, blue and green. All the colors that you can see in the screen are a mixture of these three. The spectrum a LCD screen just contains those three colors. 


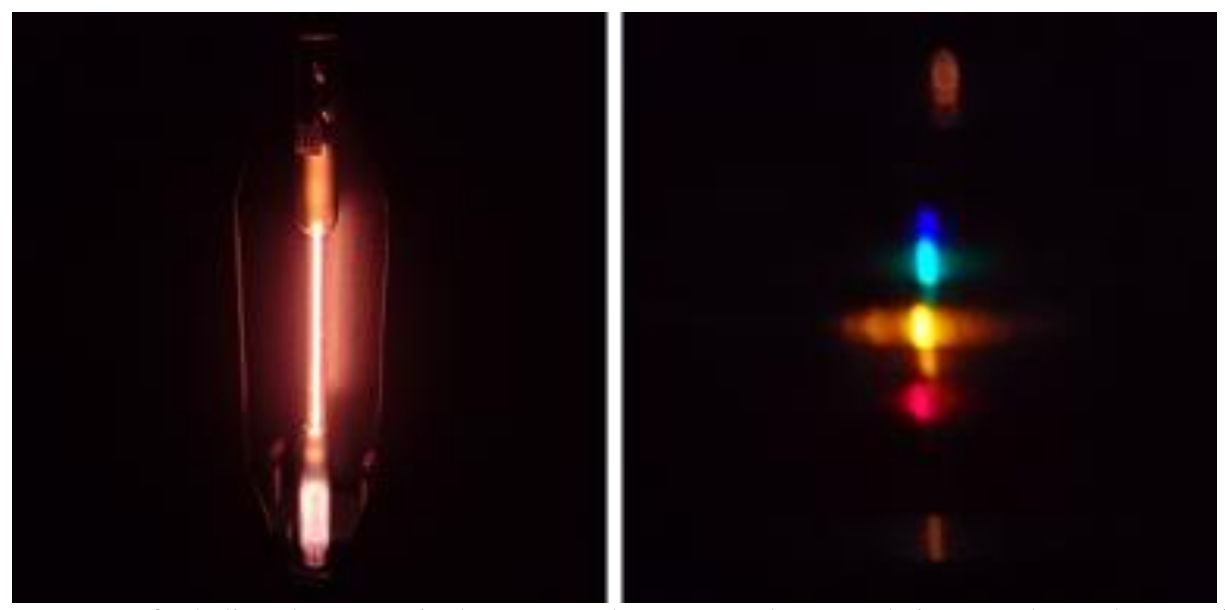

Figure 21. The spectrum of a helium lamp. Excited atoms produce spectra because their atoms have electrons in different energy levels. Electrons moving from a high energy level to a lower energy level produce light with different wavelengths, or colours.

Figure 22. The spectrum for a mercury lamp. In contrast to the helium lamp, this lamp produces a light blue and intense ultraviolet emission.
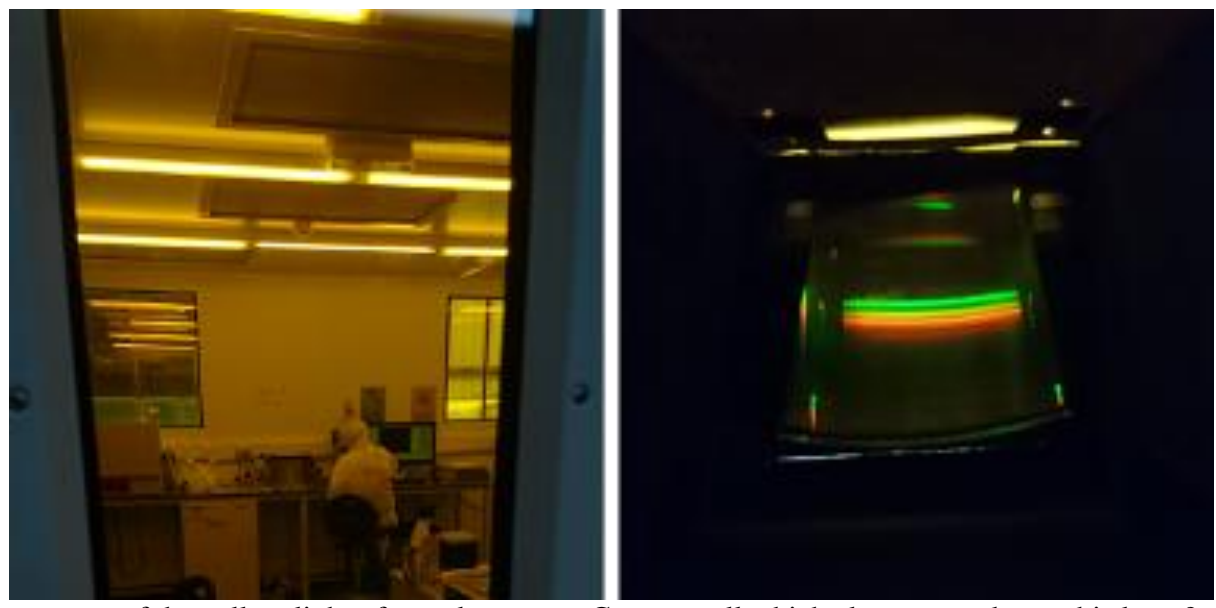

Figure 23. The spectrum of the yellow light of our cleanroom. Can you tell which elements make up this lamp? 
Hands on!

Take your spectrometer with you and find different light sources around you. Try with the following ones:

- Moon light

- A neon sign

- A street light

- A white LED source.

- What differences can you notice between these sources?

- Why some sources give discrete lines while others give a continuum spectrum?

Try to discover what elements are in the different sources using the "Visible Spectra of the Elements" table provided with this document. Have fun!

If you would like to ask us some questions about this experiment, physics or science in general, please get in touch to the following email: euops@exeter.ac.uk or Erick Burgos Parra eoburgsos@ug.uchile.cl . Erick Burgos Parra and Gloria Segovia Alvear took not acknowledged pictures. 


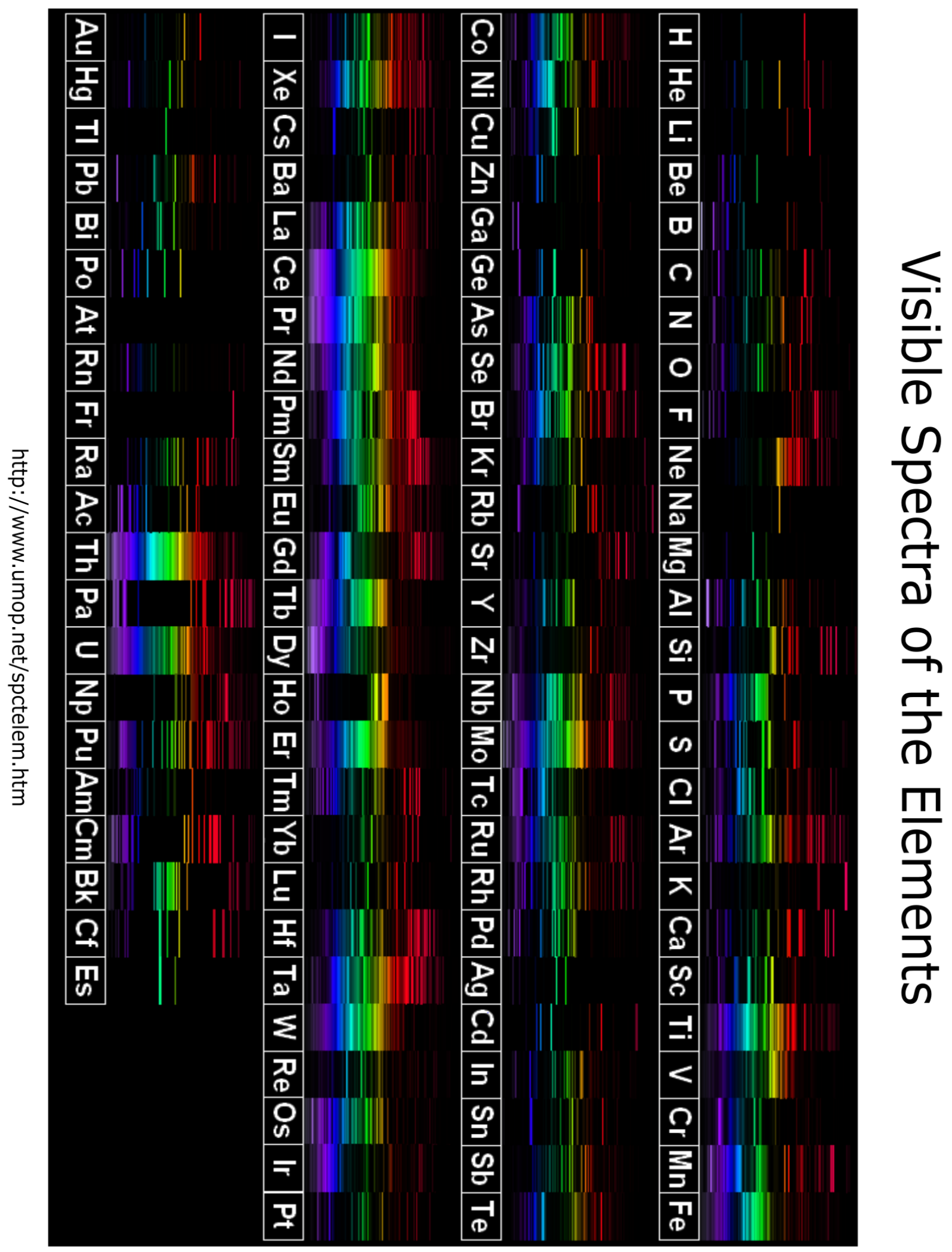

Figure 24. Visible spectra of the elements of the periodic table. 


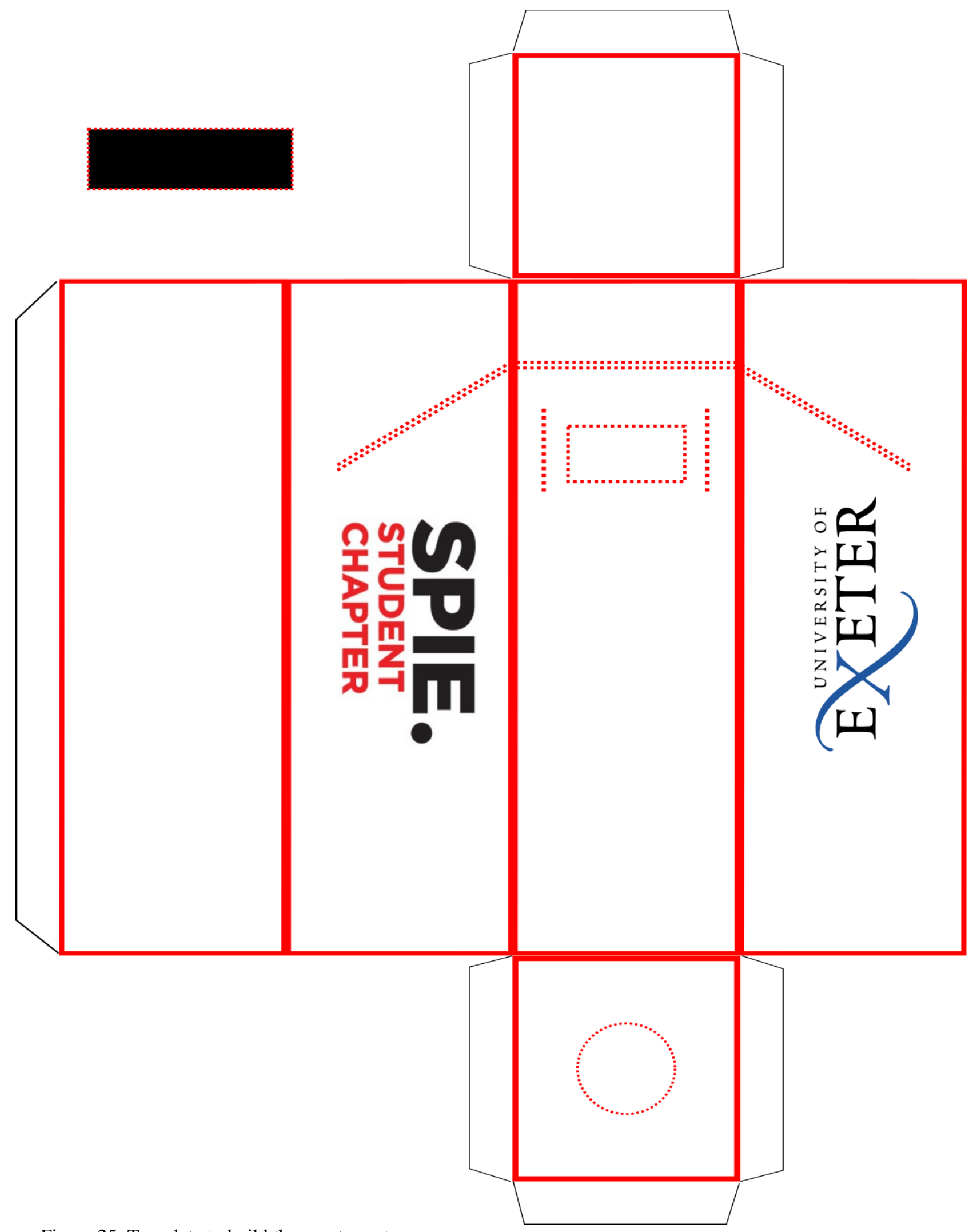

Figure 25. Template to build the spectrometer.

Proc. of SPIE Vol. 10741 107410I-17 Downloaded From: https://www.spiedigitallibrary.org/conference-proceedings-of-spie on 26 Apr 2023
Terms of Use: https://www.spiedigitallibrary.org/terms-of-use 